\title{
Pengaruh Kualitas Pelayanan Terhadap Kepuasan Peserta Bpjs Kesehatan Kc Magelang
}

${ }^{1}$ Siti Nur Faizah, Ekonomi Pembanguan Universitas Tidar Magelang

2 Jihad Lukis Panjawa, Ekonomi Pembanguan Universitas Tidar Magelang

\section{Informasi Naskah}

Submitted :29 Oktober 2020

Revision: 8 November 2020

Accepted: 29 November 2020

\section{Kata Kunci:}

Kepuasan Pelayanan, Reability, Empathy dan Assurance.

\begin{abstract}
Service delivery carried out by service personnel must refer to the main objective of service, namely customer satisfaction. This research analyzes the effect of service quality on the satisfaction of BPJS Kesehatan KC. Using quantitative research methods and primary data using sampling techniques using the Slovin formula using 100 respondents from a total of 1027437 BPJS Kesehatan participants. By using variables tangible, reliability, responsiveness, assurance, and empathy are used to measure the satisfaction of participant services. The results of this study $R$ square (coefficient of determination) obtained $R$ Square value of 0.788 (78.8\%), which means $78.8 \%$ of service satisfaction variables are influenced by tangible variables, reliability, responsiveness, empathy, and assurance and the remaining other variables outside the research variables. There is a partially significant effect consisting of the variable reliability, empathy, and assurance that affect service satisfaction. While variables tangible and responsiveness do not affect customer satisfaction. BPJS Kesehatan KC Magelang must pay more attention and improve service quality factors, namely tangible and responsiveness so as to provide service satisfaction for participants
\end{abstract}




\section{PENDAHULUAN}

Badan Penyelenggara Jaminan Sosial (BPJS) Kesehatan merupakan badan hukum publik yang bertugas untuk menyelenggarakan Jaminan pemeliharaan kesehatan bagi seluruh rakyat Indonesia. Dan Setiap rakyat Indonesia wajib untuk mempunyai kartu Indonesia Sehat yang dikelola BPJS Kesehatan (Abidin, 2016; Kesehatan, 2014). Badan Penyelenggara Jaminan Kesehatan Sosial (BPJS) Kesehatan merupakan Badan Hukum Publik yang ditugaskan khusus oleh pemerintah untuk menyelenggarakan jaminan pemeliharaan kesehatan bagi seluruh rakyat Indonesia, terutama untuk Pegawai Negeri Sipil, Penerima Pensiun PNS dan TNI/Polri, veteran, perintis kemerdekaan beserta keluarganya dan usaha lainnya ataupun rakyat biasa.

Setiap tahun peserta BPJS Kesehatan mengalami peningkatan dari tahun ke tahun. Pada tahun 2014 peserta BPJS Kesehatan sebanyak 133.4 juta jiwa, pada tahun 2015 naik mencapai 156.7 juta jiwa, tahun 2016 menyentuh 171.939.254 jiwa. Pada tahun 2017 jumlah peserta BPJS Kesehatan mengalami kenaikan sebanyak 188 juta jiwa dan pada tahun 2018 peserta BPJS Kesehatan mencapai 197.4 juta jiwa. Dan pada tahun 2019 peserta BPJS mencapai $83 \%$ dari jumlah penduduk yaitu 224.1 juta jiwa. Naiknya peserta BPJS Kesehatan juga akan berpengaruh terhadap pelayanan Petugas BPJS terhadap peserta.

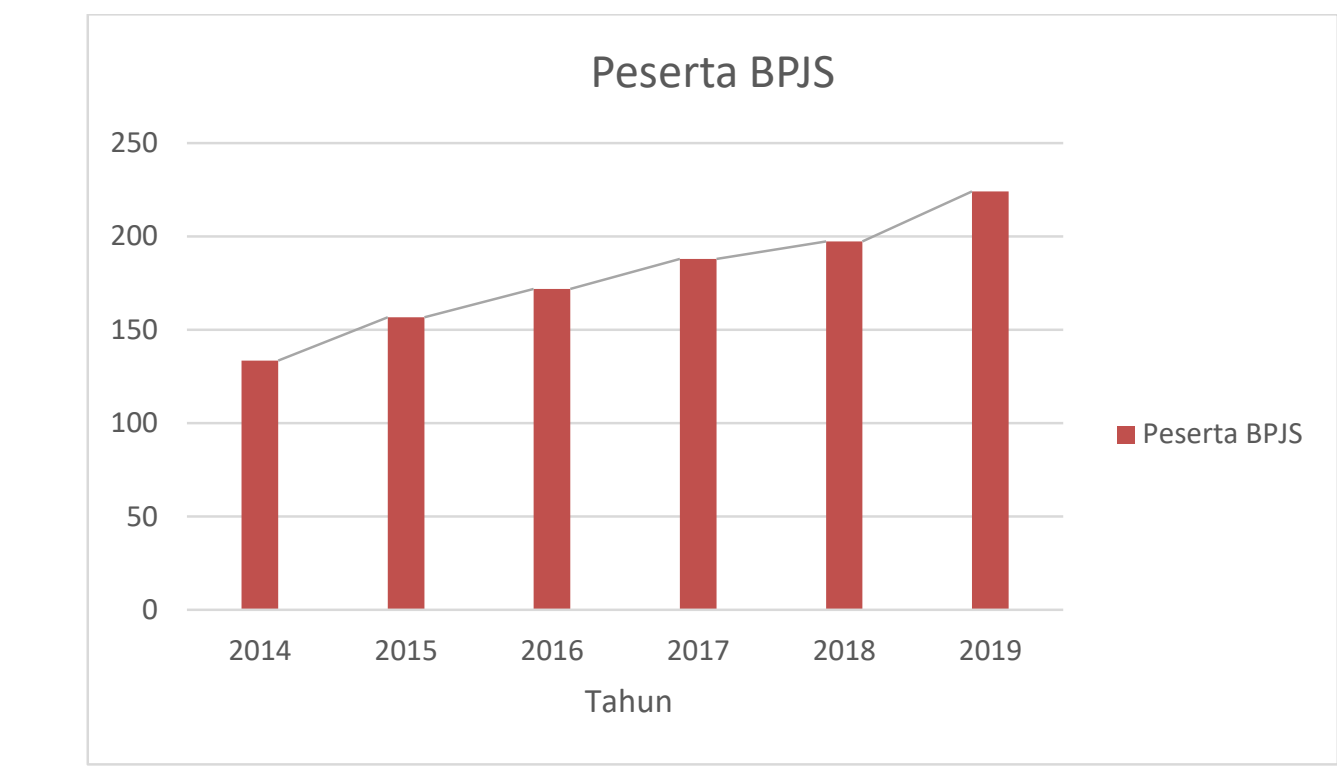

Sumber : BPJS Kesehatan

Gambar 1. Peserta BPJS Kesehatan tahun 2014-2019 dalam Juta Jiwa

Melihat Survey dari BPJS Call Center Pusat melebihi target yang diharapakan melalui lembaga survey ternama, Myriad Research Comitted, dari Responden masyarakat sebanyak 17.280 sebanyak $80 \%$ menyatakan puas terhadap BPJS Kesehatan dimana melampaui target yang ditetapakan Pemerintah sebesar 75\% (Kesehatan, 2015). Banyaknya Fasilitas kesehatan yang sudah bekerja sama dengan BPJS Kesehatan mempengaruhi Kepuasan Peserta BPJS. Dengan Peningkatan Kepuasan Peserta JKN-KIS dari segi Kualitas sudah gencar dilakukan oleh BPJS Kesehatan dengan tujuan agar semua peserta mendapatkan pelayanan kesehatan yang adil dan merata (Kesehatan, 2019).

Pelayanan atau Jasa yang dirasakan pelanggan harus dijaga secara terus menerus agar dapat mengetahui kekurangan dari pelayanan sehingga dapat diatasi (Chalis Fajri Hasibuan, 2017; Putranti, 2016). Kepuasan Pelayanan bias diukur menggunakan dimensi kualitas pelayanan antara lain : tangible (tampilan fisik), Reliability (keandalan), Responsiveness, Assurance dan Empathy (Hayworth, Hobson, \& Mia, 2012; Khoirista, Yulianto, \& Mawardi, 2015). Tujuan dari penelitian ini adalah untuk menganalisis kualitas pelayanan terhadap kepuasan peserta BPJS Kesehatan KC Magelang dengan menggunakan Variabel tangible (tampilan Fisik), Reability (kehandalan), Responsivines, Empati dan Asurance 
(jaminan). Dalam jurnal penelitian (Abidin, 2016; Darmawan \& Ajib, 2018; Dianita \& Latifah, 2017) digunakan untuk mengetahui hubungan antara variabel-variabel terhadap kepuasan layanan. Selain itu menggunkan penelian terdahulu yang dilakukan oleh (Ababa, 2016; Abidin, 2016; Bandu, 2013; Darmawan \& Ajib, 2018; Dianita \& Latifah, 2017; Hamid, 2019; Irwanto \& Akbar, 2017; Khoirista et al., 2015; Putranti, 2016; Udjang \& Subarjo, 2019).

Setiap tahunnya peserta BPJS Kesehatan mengalami peningkatan baik peserta yang golongan mandiri, berasal dari perusahaan maupun peserta bebas iuran (PBI). Untuk Peserta BPJS Kesehatan Kota Magelang terdapat 113.309 Peserta dan Kabupaten Magelang ada 914.128 peserta. Hal ini menunjukan adanya kenaikan peserta BPJS Kesehatan. Dengan naiknya peserta, BPJS Kesehatan sebagai perusahaan jasa perlu memperhatikan pelayanannya guna mencapai kepuasan pelayanan. Penelitian ini membahas tentang pengaruh kualitas pelayanan terhadap kepuasan pelanggan di BPJS Kesehatan KC Magelang. Yang diukur menggunakan dimensi kualitas pelayanan antara lain variabel tangible (tampilan Fisik), Reability (kehandalan), Responsivines (daya tanggap), Empathy (empati) dan Asurance (jaminan)yang digunakan untuk mengukur kepuasan pelayanan. Penelitan ini bertujuan untuk :

1. Menganalisis kualitas pelayanan terhadap kepuasan peserta BP5g JS Kesehatan KC Magelang.

2. Variabel apa saja yang mempengaruhi kepuasan pelayanan di BPJS Kesehatan KC Magelang.

Dalam pelayanan BPJS Kesehatan tingkat Kepuasan peserta BPJS merupakan hal yang penting. Sebagai perusahaan yang bergerak dalam bidang Jasa Kepuasaan pelayanan perlu diperhitungkan untuk meningkatkan mutu pelayanan dan kepuasan bagi peserta BPJS Kesehatan (Abidin, 2016; Chalis Fajri Hasibuan, 2017; Irwanto \& Akbar, 2017). Menurut Philip Kotler (2006: 47) Kepuasan merupakan tingkat perasaan yang dirasakan oleh seseorang yang dibandingkan dengan harapan. Sedangkan menurut Muninjaya (2011:13) kepuasan pelayanan adalah sebuah anggapan seseorang terhadap tingkat harapan seseorang sebelum dan sesudah menerima jasa pelayanan. Kualitas pelayana merupakan berapa jauh perbedaan antara harapan dan kenyataan yang diterima seseorang atas layanan yang diberikan oleh jasa pelayanan (Dianita \& Latifah, 2017; Khoirista et al., 2015).

Dalam dimensi kualitas Pelayanan menurut (Ababa, 2016; Chalis Fajri Hasibuan, 2017; Hardiyati, 2010; Ravallion, 2004) terdapat lima dimensi kualitas pelayanan yang menunjukan kualitas pelayanan untuk persepsi pelanggan, Antara lain :

1. Tangible (bukti fisik)

Kemampuan dari suatu perusahaan dalam menampilkan sarana fisik dan keadaan lingkungan yang merpakan bukti nyata dan pelayanan yang diberikan.

2. Reliability (kehandalan)

Kemampuan dari suatu perusahaan untuk memberikan pelayanan sesuai dengan yang dijanjikan secara akurat dan terpercaya.

3. Resposiviness (Daya tanggap)

Kemapuan pegawai untuk menyapaikan Informasi yang jelas, mudah dipahami dan memberikan pelayanan yang cepat dan tepat. Hal ini berkaitan dengan pemberian jasa secara maksimal dan bertanggung Jawab.

4. Empathy (Empati)

Kepedulain dan Perhatian para pegawai terhadap pelanggan. Dengan kemampuan memberikan perhatian yang khlas dan memahami kesulitan atau masalah pelanggan.

5. Assurance (Jaminan) Kemampuan para pegawai untuk menumbuhkan kepercayaan dan keyakinan pelanggan yang ada kaitannya dengan kesopanan dan pengetahuan.

\section{METODOLOGI PENELITIAN}

\section{Lokasi Dan waktu Penelitian}


Penelitian ini dilakukan di BPJS Kesehatan Kantor Cabang Magelang Jalan Bulurejo, Mertoyudan Jln. Jend Gatot Soebroto No. 2 Seneng 1 Jurang Ombo Sel., Kec. Magelang Selatan, Kota Magelang, Jawa Tengah. Untuk penelitian sendiri dilaksankan selama 2 bulan dari bulan Januari sampai dengan bulan Febuari 2020.

\section{Jenis Penelitian dan Metode Pengambilan Sampel}

Jenis Penelitian

Penelitian ini menggunakan metode deskriptif Kuantitatif yang bertujuan bertujuan untuk menganalisis kualitas pelayanan terhadap kepuasan peserta BPJS Kesehatan KC Magelang. Dengan teknik pengumpulan data menggunakan Kuisioner langsung ke peserta BPJS Kesehatan.

Sampel dan teknik Pengambilan Sampel

Sampel yan digunakan pada penelitian ini menggunakan 100 responden dengan berdasarkan perhitungan menggunakan rumus Slovin sebagai berikut :

Dimana

$$
\begin{gathered}
n=\frac{N}{1+N e^{2}} \\
n=\frac{1027437}{1+1027437(10 \%)^{2}} \\
\mathrm{n}=99.99
\end{gathered}
$$

$\mathrm{n}=$ ukuran sampel

$\mathrm{N}$ = Banyak populasi sebanyak 1027437 dari penjumlahan jumlah peserta BPJS

Kesehatan Kota Magelang dan Kabupaten Magelang

$\mathrm{e}=$ Persen kelonggaran ketidakpastian karena kesalahanpengambilan sampel. .

\section{Teknik analisis}

Teknik analisis yang digunakan dalam penelitian ini menggunakan analisis deksripsi dan regresi sederhana. Analisis yang digunakan dalam penelitian ini mencangkup uji validitas, uji reabilitas, uji koefesien determinasi, uji f, dan uji regresi berganda

\section{Variabel dan skala pengukuran}

Variabel variable yang digunakan pada penelitian dapat dilihat dalam tabel berikut :

\section{Tabel 1}

\begin{tabular}{|c|c|c|}
\hline \multirow[t]{4}{*}{ Konsep } & Variabel & $\begin{array}{c}\text { Indikator } \\
\text { 1. Tempat di lingkungan BPJS Bersih dan nyaman }\end{array}$ \\
\hline & $\begin{array}{l}\text { Tangible } \\
\quad(\mathrm{X} 1)\end{array}$ & $\begin{array}{l}\text { 2. Peralatan, perlengkapan dan sarana yang lengkap dan } \\
\text { modern } \\
\text { 3. Penampilan petugas rapi dan professional } \\
\text { 1. Pelayanan sesuai jam operasional }\end{array}$ \\
\hline & Realibility & 2. Pelayanan pengaduan cepat dan handal \\
\hline & (X2) & $\begin{array}{l}\text { 3. Informasi disampaikan sesuai dengan yang dibutuhkan } \\
\text { peserta }\end{array}$ \\
\hline \multirow[t]{3}{*}{$\begin{array}{l}\text { Kualitas } \\
\text { Pelayanan } \\
\text { (X) }\end{array}$} & $\begin{array}{l}\text { Responsivenes } \\
\text { (X3) }\end{array}$ & $\begin{array}{l}\text { 1. Petugas menyampaikan informasi kepada peserta dengan } \\
\text { jelas dan mudah dimengerti } \\
\text { 2. Respon petugas cepat dalam pelayanan peserta } \\
\text { 3. Kesiapan petugas dalam melayani peserta } \\
\text { 1. Petugas memberikan perhatian sepenuh hati terhadap }\end{array}$ \\
\hline & $\begin{array}{l}\text { Emphaty } \\
\qquad(X 4)\end{array}$ & $\begin{array}{l}\text { Peserta } \\
\text { 2. Petugas tidak membedakan status sosial/penampilan peserta } \\
\text { 3. Petugas mengutamakan peserta yang urgent (sangat } \\
\text { membutuhkan) }\end{array}$ \\
\hline & Assurance & 1. Petugas mampu menanamkan Kepecayaan kepada Peserta \\
\hline
\end{tabular}

\section{Konsep, variabel dan Indikator Penelitian}


(X5) 2. Petugas mampu menjawab setiap Pertanyaan dari Peserta

3. BPJS Kesehatan memiliki Citra yang baik dimata masyarakat

1. Petugas selalu menangapi keluhan Peserta BPJS

Kepuasan Tingkat

Pelanggan Kepuasan

(Y) Pelanggan
2. Petugas memberikan pelayanan jasa yang memuaskan peserta BPJS

3. BPJS Kesehatan memiliki relasi fasilitas kesehatan yang luas

4. Secara keseluruhan peserta menilai bahwa BPJS Kesehatan $\mathrm{KC}$ magelang memiliki Citra yang baik

Sumber : data Olahan Penulis (2020)

\section{HASIL DAN PEMBAHASAN}

\section{Hasil Penelitian}

Dari hasil penelitian didapatkan di BPSJ Kesehatan Kantor Cabang magelang dengan mengunakan 100 responden mayoritas responden adalah laki-laki sebesar 53\% (53 responden) dan sisanya merupakan responden wanita sebesar 47\% (47 responden). Untuk umur sendiri 20 sampai 30 tahun sebanyak 30\% (30 responden), umur 31 sampai 40 sebanyak $31 \%$ ( 31 responden), umur dari 41 sampai 50 ada $21 \%$ ( 21 responden) dan umur lebih dari 51 tahun sebanyak 18\% (18 responden). Untuk Pekerjaan PNS sebanyak $11 \%$ ( 11 responden), Wiraswasta $7 \%$ ( 7 responden), Karyawan swasta ada $11 \%$ ( 11 responden) dan yang mayoritas mengisi lainnya ada 62\% ( 62 responden) dengan pekerjaan ada Buruh, Petani, Ibu rumah tangga dan lainnya. Untuk iuran Kartu BPJS Kesehatan mayoritas adalah mandiri sebesar 53\% ( 53 responden), kemudian PBI sebesar 43\% ( 43 responden) dan Pekerja sebanyak 4\%( 4 responden). Yang dapat dilihat pada tabel dibawah :

Table 2.

Karakteristik Responden

\begin{tabular}{|c|c|c|}
\hline Karakteristik & Frekuensi & Persen \\
\hline \multicolumn{3}{|l|}{ Umur } \\
\hline $20-30$ & 30 & $61 \%$ \\
\hline $31-40$ & 31 & \\
\hline $41-50$ & 21 & $33 \%$ \\
\hline$>51$ & 18 & $6 \%$ \\
\hline Jenis Kelamin & & \\
\hline Laki - Laki & 53 & $53 \%$ \\
\hline $\begin{array}{l}\text { Perempuan } \\
\text { Pekerjaan }\end{array}$ & 47 & $47 \%$ \\
\hline PNS & 11 & $11 \%$ \\
\hline $\begin{array}{l}\text { Karyawan } \\
\text { Swasta }\end{array}$ & 20 & $20 \%$ \\
\hline Wiraswasta & 7 & $7 \%$ \\
\hline $\begin{array}{l}\text { Lainnya } \\
\text { luran }\end{array}$ & 62 & $62 \%$ \\
\hline PBI & 43 & $43 \%$ \\
\hline Mandiri & 53 & $53 \%$ \\
\hline Pekerja & 4 & $4 \%$ \\
\hline
\end{tabular}

\section{Uji Validitas Dan Reliabilitas}

\section{Uji Validitas}

Pengujian Validitas yang dilakukan dengan menggunakan metode analisa corelasi dengan bantuan progam SPSS menghasilkan perhitungan sebagai berikut : 
Tabel.3

Hasil Uji Validitas

\begin{tabular}{rlccc}
\hline No & \multicolumn{1}{c}{ Variabel } & rhitung & r tabel & Ket \\
\hline 1 & Tangible & & & \\
& TG 1 & 0.912 & 0.197 & Valid \\
& TG 2 & 0.933 & 0.197 & Valid \\
& TG 3 & 0.900 & 0.197 & Valid \\
2 & Realibility & & & \\
& R1 & 0.919 & 0.197 & Valid \\
& R2 & 0.891 & 0.197 & Valid \\
& R3 & 0.913 & 0.197 & Valid \\
3esponsivenes & & & \\
& RS1 & 0.944 & 0.197 & Valid \\
& RS2 & 0.940 & 0.197 & Valid \\
& RS3 & 0.966 & 0.197 & Valid \\
4mphaty & & & \\
& E1 & 0.946 & 0.197 & Valid \\
& E2 & 0.93 & 0.197 & Valid \\
& E3 & 0.917 & 0.197 & Valid \\
5 Assurance & & & \\
& A1 & 0.964 & 0.197 & Valid \\
& A2 & 0.935 & 0.197 & Valid \\
& A3 & 0.889 & 0.197 & Valid \\
\hline
\end{tabular}

Dari Hasil uji Validitas, indikator indikator yang digunakan untuk mengukur variabel variable yang digunakan dalam penelitian mempunyai korelasi lebih besar dari $r$ table (0.197) sehingga dapat dinyatakan bahwa indikator indikator dinyatakan valid.

\section{Uji Reliabilitas}

Uji reliabilitas dalam penelitian ini menggunkanan rumus Cronbath. Uji reliabilitas merupakan uji kehandalan yang digunakan untuk mengetahui seberapa jauh alat ukur tersebut dipercaya dan handal. Alat ukur dikatakan reliabel apabila jawaban responden stabil dan variable dikatakan reliabel jika nilai cronbath alpha lebih besar dari 0.70 .

\section{Tabel.4}

Hasil Uji Reliabilitas

\begin{tabular}{rlrl}
\hline No. & Variabel & Alpha & Ket \\
\hline 1 & Tangible & 0.903 & Reliabel \\
2 & Realibility & 0.893 & Reliabel \\
3 & Responsivenes & 0.946 & Reliabel \\
4 & Emphaty & 0.923 & Reliabel \\
5 & Assurance & 0.923 & Reliabel \\
6 & Kepuasan & 0.930 & Reliabel \\
\hline
\end{tabular}

Dari hasil uji reliabilitas menunjukan variabel mempunyai nilai nilai cronbath alpa lebih besar dari 0.70 sehingga dapa nilai cronbath alpa. Sehingga dapat dikatakan variable reliabel.

\section{Tabel.5}

Koefesien korelasi dan Determinasi

Model Summaryb

\begin{tabular}{cccccc}
\hline Model & $\mathrm{R}$ & $\mathrm{R}$ Square & $\begin{array}{c}\text { Adjusted } \\
\mathrm{R} \text { Square }\end{array}$ & $\begin{array}{c}\text { Std. Error of the } \\
\text { Estimate }\end{array}$ & Durbin-Watson \\
\hline 1 &, $887^{\mathrm{a}}$ &, 788 &, 776 &, 7898 & 1,958 \\
\hline
\end{tabular}

a. Predictors: (Constant), A, T, R, RS, E

b. Dependent Variable: KP 
Dari hasil uji tersebut diperoleh nilai $R^{2}$ sebesar 0.788 (78.8\%). Yang merupakan besar kontribusi variabel tangible, reability, responsiveness, empati, dan assurance terhada111111p kepuasan pelanggan sebesar $0.788(78.8 \%)$ dan sisanya $0.212(21.2 \%)$ variabel diluar model yang mempengaruhi kepuasan pelayanan.

Tabel.6

Uji F

ANOVAa

\begin{tabular}{cccccc}
\hline Model & Sum of Squares & Df & Mean Square & F & Sig. \\
\hline Regression & 217,322 & 5 & 43,464 & 69,676 &, $000^{\mathrm{b}}$ \\
\hline
\end{tabular}

a. Dependent Variable: KP

b. Predictors: (Constant), A, T, R, RS, E

Dari hasil perhitungan diatas, menunjukan bahwa Uji $F$ hitung sebesar 69.676 dengan signifikan sebesar $f(0.00)$. Maka dapat disimpulkan bahwa variable tangible, reability, responsiveness, empati dan assurance berpengaruh positif dan signifikan terhadap kepuasan pelayanan.

\section{Tabel.7}

Hasil Analisis Regresi Berganda

\begin{tabular}{|c|c|c|c|c|c|c|c|}
\hline \multicolumn{8}{|c|}{ Coefficients $^{\mathrm{a}}$} \\
\hline Model & \multicolumn{2}{|c|}{$\begin{array}{c}\text { Unstandardized } \\
\text { Coefficients }\end{array}$} & $\begin{array}{c}\text { Standardized } \\
\text { Coefficients }\end{array}$ & $\mathrm{t}$ & Sig. & \multicolumn{2}{|c|}{$\begin{array}{l}\text { Collinearity } \\
\text { Statistics }\end{array}$} \\
\hline & B & $\begin{array}{l}\text { Std. } \\
\text { Error }\end{array}$ & Beta & ,707 & ,481 & Tolerance & VIF \\
\hline 1 (Constant) &, 514 &, 727 & &,- 861 & 391 & & \\
\hline $\mathrm{T}$ &,- 084 & ,098 &,- 062 & 2,196 & ,031 & 433 & 2,311 \\
\hline $\mathrm{R}$ & ,308 & 140 & ,218 &,- 822 & ,413 & 229 & 4,361 \\
\hline RS &,- 104 &, 126 &,- 080 & 3,245 & 002 & ,239 & 4,192 \\
\hline $\mathrm{E}$ &, 504 & , 155 & ,375 & 5,401 & ,000 & 169 & 5,919 \\
\hline A & ,658 &, 122 & ,474 &, 707 & ,481 & ,293 & 3,408 \\
\hline
\end{tabular}

a. Dependent Variable: KP

Dari perhitungan diatas maka dapat disusun persamaan regresi sebagai berikut :

$Y=\alpha+\beta 1 X 1+\beta 2 X 2+\beta 3 X 3+\beta 4 X 4+\beta X 5+e$

$Y=0.512-0.084 X 1+0.308 X 2-0.104 X 3+0.504 X 4+0.658 X 5+e$

Sehingga dari persamaan regresi dapat dijabarkan sebagai berikut :

1. Nilai Konstanta sebesar 0.512 , menunjukan bahwa semakin meningkatnya pelayanan maka akan berpengaruh terhadap kepuasan pelayanan.

2. Koefesien regresi dari variabel tangible sebesar -0.084 yang berarti setiap kenaikan variable tangible akan menaikan kepuasan pelayanan -0.084 .

3. Koefesien dari variabel reability sebesar 0.308 maka setiap kenaikan variabel akan menaikan kepuasan sebesar 0.308

4. Koefesien dari variabel responsiviness sebesar -0.104 maka setiap kenaikan variabel akan menaikan kepuasan sebesar -0.104

5. Koefesien dari variabel empathy sebesar 0.504 maka setiap kenaikan variabel akan menaikan kepuasan sebesar 0.504

6. Koefesien dari variabel assurance sebesar 0.308 maka setiap kenaikan variabel akan menaikan kepuasan sebesar 0.658

Dari hasil regresi menunjukan bahwa variabel reability, empathy dan assurance berpengaruh positif terhadap kepuasan pelayanan peserta BPJS Kesehatan KC Magelang. Sedangkan variabel tangible dan variable responsiviness berpengaruh negative terhadap 
kepuasan pelayanan di BPJS Kesehatan KC Magelang.

\section{Pembahasan}

Hasil dari penelitian ini menunjukan bahwa variabel yang mempengaruhi kepuasan pelayanan adalah reability,empati dan asuransi. Variabel reability (Kehandalan) mempengaruhi kepuasan pelayanan sebesar 0.308 yang meliputi dalam pelayanan yang dilakukan sesuai jam operasional, pelayanan pengaduan yang cepat dan handalserta informasi yang disampaikan sesuai dengan yang diharapakna oleh peserta. Variabel emphaty (empati) mempengaruhi kepuasan pelayanan sebesar 0.504 yang diperoleh dari perhatian petugas terhadap peserta, sikap petugas yang tidak membeda-bedakan status maupun penampilan pesertaserta petugas yang lebih pengutamakan peserta yang sangat membutuhkanatau dalam keadaan terdesak. Dan variabel assurance (jaminan) mempengaruhi kepuasan pelayanan terbesar yakni sebesar 0.658 yang menunjukan bahwa pesera percaya terhadap petugas BPJS Kesehatan dan juga citra BPJS Kesehatan dimata masyarakat luar dipandang baik.

Sedangkan untuk variabel vangible (tampilan fisik) yang meliputi lingkungan BPJS, sarana prasaranan serta penampilan petugas dan variabel Responsivenes ( daya tanggap) yang meliputi penyampain informasi, respon petugas dan kesigapan petugas dalam melayani kurang berpengaruh terhadap kepuasan peserta. Agar peserta merasa puas dalam dalam pelayanannya, maka BPJS Kesehatan harus terus menerapkan dan meningkatkan faktor yang bersifat tanggap, sarana dan prasarana dan lingkungan.

\section{KESIMPULAN DAN SARAN}

\section{Kesimpulan}

Berdasarkan hasil penelitian penulis untuk bertujuan untuk menganalisis kualitas pelayanan terhadap kepuasan peserta BPJS Kesehatan KC Magelang, maka dapat diperoleh kesimpulan bahwa kualitas pelayanan di BPJS Kesehatan KC Magelang dipengaruhi oleh variabel reability ( kehandalan), Empathy (empati) dan Assurance (jaminan). Variabel empathy (empati) memberikan pengaruh paling besar terhadap kepuasan pelayanan. Sedangkan variabel tangible (tampilan fisik) dan responsiviness (daya tanggap) di BPJS Kesehatan perlu untuk ditingkatkan dan diperbaiki kedepannya.

\section{Saran}

Saran saya berdasarkan hasil penelitian dan pembahasan, BPJS Kesehatan lebih memperhatikan dan meningkatkan tampilan fisik seperti penataan perlengkapan, peralatan dan saranan yang lebih rapi dan indah, penampilan petugas yang lebih rapi dan profesional, penataan tempat antri dan parkir motor yang lebih fleksibel dan tertata. Serta meningkatkan dan memperbaiki faktor daya tanggap seperti penyampaian informasi petugas yang lebih jelas dan menggunakan bahasa yang mudah dipahami oleh peserta, meningkatkan respon pelayanan dan kesigapan dalam melayani peserta sehingga dapat meningkatkan kepuasan pelayanan.

\section{DAFTAR PUSTAKA}

Ababa, A. (2016). Assessment Of Factors Affecting Customer Satisfaction On The Mobile Service Of Ethio Telecom.

Abidin. (2016). Pengaruh Kualitas Pelayanan Bpjs Kesehatan Terhadap Kepuasan Pasien Di Puskesmas Cempae Kota Parepare. JURNAL MKMI, 12(2), 70-75.

Bandu, M. U. H. Y. (2013). Pengaruh Kualitas Pelayanan Terhadap Kepuasan Pelanggan pada PT . PLN ( Persero ) Rayon Makassar Barat.

Chalis Fajri Hasibuan, S. (2017). Identifikasi Tingkat Kualitas Pelayanan Jasa Pendidikan Dengan menggunakan Servqualdi Fakultas Teknik Universitas X. Spektrum Industri ISSN : 1963-6590 (Print) ISSN : 2442-2630 (Online), 15(1), 1 - 8. 
Darmawan, Z. C., \& Ajib, A. A. R. (2018). Pengaruh Kualitas Pelayanan Terhadap Kepuasan Nasabah Perbankan Syariah. Jurnal Ekonomi Dan Bisnis Islam P-ISSN: 2460-9404; EISSN: 2460-9412 DO Http://Dx.Doi.Org/10.21093/at.V3i2.1096, 3(2), 107-116.

Dianita, P. S., \& Latifah, E. (2017). Tingkat Kepuasan Pasien Terhadap Pelayanan Obat Di Apotek Wilayah Kecamatan Mertoyudan Kabupaten Magelang. Jurnal Farmasi Sains Dan Praktis, Vol. III, No. 2, November, III(2), 19-23.

Hamid, L. (2019). Pengaruh Kualitas Pelayanan Terhadap Kepuasan Pelanggan Pada Bengkel Hnf Motor Gemolong.

Hardiyati, R. (2010). Terhadap Kepuasan Konsumen Menggunakan Jasa Penginapan ( Villa ) Agrowisata Kebun Teh Pagilaran.

Hayworth, C., Hobson, R., \& Mia, Z. (2012). Examining the effect of retail service quality dimensions on customer satisfaction and loyalty: The case of the supermarket shopper Customer Satisfaction versus Perceived Service Quality. (2006), 27-43.

Irwanto, \& Akbar, R. (2017). Analisis kepuasan masyarakat terhadap pelayanan pembuatan jkn pada bpjs kesehatan 1,2. Jurnal Bisnis Administrasi, 06(2), 47-56.

Kesehatan, B. (2014). Pedoman Umum Tata Kelola Yang Baik (Good Governance) Bpjs Kesehatan. BPJS Kesehatan, pp. 1-34.

Kesehatan, B. (2015). Indeks Kepuasan Peserta dan Faskes terhadap BPJS Kesehatan Sukses Lampaui Target. Departemen Komunikasi Dan Hubungan Masyarakat BPJS Kesehatan Kantor Pusat Humas @bpjs-Kesehatan.Go.Id, p. 2.

Kesehatan, B. (2019). Siaran pers Prioritaskan Kepuasan Peserta, Mutu Layanan Faskes Tingkat Pertama Jadi Fokus BPJS Kesehatan. Humas BPJS Kesehatan BPJS Kesehatan Kantor Pusat Humas@bpjs-Kesehatan.Go.ld Www.Bpjs-Kesehatan.Go.ld, pp. 1-2.

Khoirista, A., Yulianto, E., \& Mawardi, M. K. (2015). Pengaruh Kualitas Pelayanan Terhadap Kepuasan Pelanggan (Survey Pada Pelanggan Fedex Express Surabaya). Jurnal $\begin{array}{lllllll}\text { Administrasi Bisnis (JAB) Vol. } 25 & \text { No. } 2 & \text { Agustus } & 2015\end{array}$ Administrasibisnis.Studentjournal.Ub.Ac.Id, 25(2), 1-7.

Putranti, A. (2016). Analisis Kepuasan Pasien Terhadap Kualitas Pelayanan Perawatan Gigi Di Klinik Gigi My Dental Care. Jurnal Penelitian Kesehatan Suara Forikes ISSN 2086-3098 (Cetak) ISSN 2502-7778 (Elektronik), VII(3), 201-207.

Ravallion, M. (2004). Growth, Inequality, and Poverty: Looking Beyond Averages. World

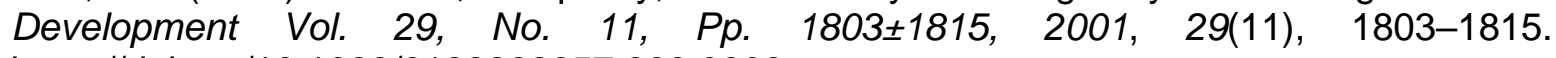
https://doi.org/10.1093/0199268657.003.0003

Udjang, R., \& Subarjo. (2019). Analisis Tingkat Kepuasan Mahasiswa Pada Kualitas Layanan Universitas Mercu Buana Yogyakarta. JPSB, 7(1), 64-75. 